\title{
Edema and gingival bleeding in anterior region have a negative influence on quality of life of adolescents
}

\section{Marília Cunha MARONEZE(a) Lucas Miers GOERGEN(a) \\ Rae Cristian Lanza de SOUZA(a) José Mariano da ROCHA(a) Thiago Machado ARDENGHI ${ }^{(a)}$}

(a) Universidade Federal de Santa Maria UFSM, Faculty of Dentistry, Department of Stomatology, Santa Maria, RS, Brazil.

Declaration of Interests: The authors certify that they have no commercial or associative interest that represents a conflict of interest in connection with the manuscript.

\section{Corresponding Author:}

Thiago Machado Ardenghi

E-mail: thiardenghi@hotmail.com

htps://doi.org/10.1590/1807-3107bor-2018.vol32.0112

Submitted: April, 24, 2018

Accepted for publication: August 21, 2018

Last revision: September 11, 2018

\begin{abstract}
The aim of the present study was to verify if clinical signs of gingivitis such as color changes, edema, and bleeding in the anterior region influence the OHRQoL of adolescents. We followed a crosssectional convenience sample of 67 adolescents aged 11 to 16 years receiving dental treatment at the Federal University of Santa Maria (UFSM), in southern Brazil. The participants were evaluated for the following clinical variables: edema, gingival color alteration, and marginal bleeding of the gingival tissues, collected at 6 sites per tooth in the anterior region of the mouth. Socioeconomic variables were collected through questionnaires and OHRQoL was evaluated through the Brazilian version of the Children Perception Questionnaire (CPQ 11-14) short form. A Poisson regression model was used to verify associations between clinical variables and general CPQ11-14 scores. In the unadjusted analysis, edema, color alterations, and marginal bleeding in the anterior region were associated with worse scores of OHRQoL. Edema and marginal bleeding remained associated after adjusting for clinical and sociodemographic variables. Adolescents with higher levels of marginal bleeding and edema in the anterior region had higher mean CPQ11-14 scores. Therefore, the presence of bleeding and gingival edema in the anterior region can be considered clinical signs of gingivitis that are associated with a worse OHRQoL in adolescents.
\end{abstract}

Keywords: Adolescent; Gingivitis; Oral Health; Quality of Life.

\section{Introduction}

Oral health is a multifaceted construct and an essential factor for the quality of life of individuals. ${ }^{1}$ According to the World Health Organization, quality of life refers to the individual's perception of their position in life, cultural context, and values. ${ }^{2}$

Oral health related quality of life (OHRQoL) is a multidimensional construct that refers to the individual's self-perception about their oral health condition and involves physical, oral, social, and psychological aspects. ${ }^{3}$ This measure has also been widely used by health professionals for the evaluation of clinical practice and as a relevant outcome for assessing the effectiveness of oral health interventions. ${ }^{4}$

Data from the last national survey conducted in Brazil showed that $27.1 \%$ of 12 -year-old adolescents presented marginal bleeding of the 
gingival tissues. ${ }^{5}$ Some studies have used a $15 \%$ rate of marginal bleeding as a criterion to define gingivitis ${ }^{6}$ and found a prevalence between 90 and $100 \%$ in this age-group. ${ }^{78}$ However, there is no consensus in the literature about the criterion that should be adopted to define gingivitis in this agegroup, and different forms of measurement can produce different estimates. ${ }^{9,10,11,12}$

Numerous studies have demonstrated that gingivitis follows a socioeconomic gradient and the disease is more frequent in individuals with higher social vulnerability. ${ }^{9,13,14,15}$ Recent studies have shown that gingivitis has a negative impact on the OHRQL of adolescents. ${ }^{7,8,16,17,18}$ This relationship may occur because adolescents perceive the clinical signs of gingivitis, which compromise the esthetics of the smile making them feel upset, irritable, or frustrated. ${ }^{19}$ Another hypothesis suggested is that adolescents may perceive gingival bleeding during tooth brushing, which can cause worry and dissatisfaction about what others would think about their oral condition. ${ }^{8}$

Despite the usefulness of these hypotheses, it is important to recognize that research has mostly focused on the role of gingivitis on the OHRQoL of adolescents measured by marginal bleeding of the gingival tissues, with limited attention to the role of other signs of gingivitis such as edema and color alteration. ${ }^{78,16,17,18}$ Such knowledge can contribute to disease prevention and the planning of actions according to the real needs of adolescents.

To the best of our knowledge, there is no study evaluating the relationship between the signs of gingivitis such as color alteration, edema, and marginal bleeding in the anterior region and the OHRQoL of adolescents. The aim of the present study was thus to verify if these clinical signs influence the OHRQoL of adolescents.

\section{Methodology}

This cross-sectional study was carried out at the dental clinic of Federal University of the Santa Maria. Santa Maria is a town in the state of Rio Grande do Sul, Brazil, with 261.031 inhabitants being 41.784 between 10 and 18 years $^{20}$. Ethical approval was obtained from the university's ethics committee (CAAE 58267516.0.0000.5346).

\section{Sample}

A convenience sample of adolescents between 11 and 16 years of age who sought dental care at the university clinic was selected. This clinic provides free dental treatment for adolescents from Santa Maria and surroundings. Around 50 new patients per year receive dental care in this clinic. Most of these individuals are students from public schools with high social and economic vulnerability. All procedures offered to the patients are performed by dental students after clinical exams and include oral hygiene instructions, and endodontic, periodontal, operative, and surgical treatments. This study was carried out from August/2016 to October/2017.

\section{Inclusion and exclusion criteria}

All adolescents that sought dental treatment and presented at least $15 \%$ of marginal bleeding in the six surfaces of posterior and anterior teeth were included ${ }^{6}$. Patients with clinical attachment level (CAL) equal to or greater than $1 \mathrm{~mm}$ or probing depth equal to or greater than $3 \mathrm{~mm}$ were exclude to avoid patients with periodontitis. ${ }^{21}$

\section{Data collection}

The data were collected through structured questionnaires and face-to-face interviews. A questionnaire and a signed consent form were obtained from parents at the beginning of the study. A trained interviewer performed the social and demographic interview with the parents in a reserved room. The adolescent-related variables were sex (male or female), last dental visit (in the last 12 months or more than 12 months ago), and skin color (white or non-white described according to the Brazilian Census parameters). ${ }^{22}$ Household income, parents education, and mother education were collected as continuous numerical variables and then categorized as $<1.5$ or $\geq 1.5$ Brazilian Minimum Wage (BMW) and $<8$ or $\geq 8$ years of study, respectively.

Before the clinical exam, a trained interviewer applied the OHRQoL structured questions to the adolescents. The feasibility of the questionnaire was 
verified by repeating the application in 10 percent of the sample. The validated Brazilian short-form of Children Perception Questionnaire (CPQ) 11-14 $4^{23}$ was used, which evaluates the adolescent's perception of the impact of oral problems on physical and psychosocial functions. The questionnaire has 16 items distributed among 4 domains: oral symptoms (four questions), functional limitations (four questions), emotional well-being (four questions), and social well-being (four questions). ${ }^{24} \mathrm{~A}$ Likert scale is used for the answers ${ }^{25}$ and response options are "never" (0), "once or twice a week " (1), "sometimes" (2), "often" (3), "every day or almost every day" (4). The total CPQ 11-14 score is calculated by summing the responses of the 16 items and can range from 0 to 64 , with higher scores indicating greater impact.

\section{Clinical exam}

International criteria standardized by the World Health Organization for oral health surveys were used for all dental examinations. ${ }^{26}$

The adolescents were examined by one examiner that was blinded to the answers of the short form CPQ11-14 questionnaire. A Gold Standard led the process of training and calibration of the examiner. The calibration process lasted 36 hours and the first part of the training included theoretical activities and case discussions with clinical photographs. The first practical part consisted of exercises with photos and extracted teeth. Clinical examinations were than performed with adolescents in the clinic to evaluate the presence of edema, alteration of color, marginal bleeding of the gingival tissues, dental plaque, and dental caries. The training and calibration was conducted with the examiner until a reproducibility index of $90 \%$ was achieved (kappa of 0.92 ).

The adolescents were examined for the presence of edema, alteration of color and marginal bleeding of the gingival tissues in the surfaces of the upper and lower canines and incisors. As no established cutoff points are available in the literature to estimate the severity of edema, gingivitis, and color alteration, we used tertiles to categorize the variables and verify their association with OHQoL. We believed that the severity of each variable could independently be related with worse scores of OHQoL in the anterior region.

Marginal bleeding of the gingival tissues was recorded according to the gingival bleeding index. ${ }^{27}$ The six gingival sites were examined and given a score per surfaces in the anterior region. A probe was inserted and left in the sulcus for 10 seconds to observe the presence or absence of marginal bleeding.

Absence or presence of color alteration and edema were recorded for all six gingival surfaces in the anterior region. Color alteration was considered present when the gingival color differed from the normal coloration due to inflammation. Melanic pigmentations and other genetic characteristics were considered normal. Edema was considered present when the gingival tissue was swollen, with loss of contour or blunt papillae compared to a healthy gingival. ${ }^{27}$

Dental plaque and dental caries were recorded in the entire mouth. Plaque was assessed by the visible plaque index (present or absence).$^{28}$ Untreated dental caries were recorded using the decayed, missed and filled teeth index.

\section{Statistical analyses}

Data were analyzed using the software STATA 14.0 (Stata Corporation, College Station, TX, USA). Descriptive analyses were conducted to provide information about the sample. The CPQ 11-14 total score and its domains were summarized by the mean and standard deviation.

The correlation between gingival bleeding, edema, and color alteration in the posterior and anterior regions were evaluated using the Spearman correlation coefficient.

Poisson regression models were performed to assess the association between clinical variables with CPQ 11-14 total scores. A backward stepwise procedure was used to include or exclude explanatory variables in the fitting of models. Explanatory variables presenting a $p$-value $\leq 0.20$ in the univariate model were included in the multivariate model. The models were adjusted for sex, household income, dental plaque, and untreated dental caries. Explanatory variables were selected for the final models only if they had a p-value $\leq 0.05$ after adjustment. 


\section{Results}

A total of 67 adolescents (56.72\% male and $43.28 \%$ female) were eligible during the study period; there was no refusal to participate. All of the adolescents that sought for dental care in this clinic presented $15 \%$ of marginal bleeding in this data collection.

Table 1 describes the sample distribution according to sociodemographic, economical, and clinical characteristics. The majority of participants were white $(72.13 \%)$ and the mean age was $13.1(\mathrm{SD}=1.2)$ years. Regarding family income, $50 \%$ reported a

Table 1. Characteristics of the sample.

\begin{tabular}{|c|c|c|}
\hline Variable & $\mathrm{N}(\%)$ & Mean (SD) \\
\hline \multicolumn{3}{|l|}{ Sex } \\
\hline Male & 38 (56.72\%) & \\
\hline Female & 29 (43.28\%) & \\
\hline \multicolumn{3}{|l|}{ Skin color } \\
\hline White & $44(72.13 \%)$ & \\
\hline Non-white & 17 (27.87\%) & \\
\hline \multicolumn{3}{|l|}{ Mother's education } \\
\hline$\geq 8$ years & 34 (55.74\%) & \\
\hline$<8$ years & 27 (44.26\%) & \\
\hline \multicolumn{3}{|l|}{ Father's education } \\
\hline$\geq 8$ years & 35 (57.38\%) & \\
\hline$<8$ years & $26(42.62 \%)$ & \\
\hline \multicolumn{3}{|l|}{ Household income } \\
\hline$\geq 1.5$ minimum wage & $30(50.00 \%)$ & \\
\hline$<1.5$ minimum wage & $30(50.00 \%)$ & \\
\hline \multicolumn{3}{|l|}{ Last dental visit } \\
\hline $\begin{array}{l}\text { More than } 12 \text { months } \\
\text { ago }\end{array}$ & $27(45.00 \%)$ & \\
\hline In the last 12 months & $33(55.00 \%)$ & \\
\hline \multicolumn{3}{|l|}{ Dental caries } \\
\hline Without & 22 (33.00\%) & $2.84 \%$ (SD: 3.7$)$ \\
\hline With & $45(67.00 \%)$ & \\
\hline Dental Plaque & & $24.49 \%$ (SD: 18.1) \\
\hline \multicolumn{3}{|l|}{ Marginal bleeding } \\
\hline $15 \%-45 \%$ & 22 (33\%) & \\
\hline More than $45 \%$ & $45(67 \%)$ & \\
\hline
\end{tabular}

monthly payment of 1.5 the minimum wage. The prevalence of untreated dental caries was $67 \%$ in the full mouth. In relation to gingivitis, $33 \%$ of the sample presented 15 to $45 \%$ of marginal bleeding and $67 \%$ presented more than $45 \%$ of marginal bleeding in the anterior region.

The CPQ 11-14 scores ranged from 0 to 43 with an average of $11.9(\mathrm{SD}=9.3)$. The oral symptoms domain presented the highest mean scores of $4.6(\mathrm{SD}=2.7)$. The mean number of surfaces with gingival bleeding, edema, and color alteration in the posterior region was $49.6,29.52$, and $16.01 \%$ respectively. The mean number of surfaces with bleeding, edema and color alteration in the anterior region was, respectively, $54.03 \%$ (SD $=24.4) ; 43.39 \%$ (SD = 27.1), and $24.67 \%$ (SD $=20.2$ ). The mean number of surfaces with untreated caries lesions was $2.84 \%(\mathrm{SD}=3.7)$ and with dental plaque was $24.49(\mathrm{SD}=18.1)$ (Table 2).

The results demonstrated that gingivitis in the anterior region is correlated with gingivitis in the posterior region $(r=0.79 ; p=0.00)$. Edema and color alteration were also correlated between the anterior the posterior regions $(r=0.73 ; p=0.00$ and $r=0.62$; $p=0.00$ respectively).

Table 3 presents the results of unadjusted and adjusted Poisson regression analyses. The unadjusted analysis indicated that edema, alteration of color, and marginal bleeding of gingival tissues in the anterior region were associated with worse scores of OHRQoL. In the adjusted model, adolescents with higher levels of bleeding and edema in the anterior region had higher mean scores of CPQ11-14. Adolescents with a higher prevalence of color alteration presented lower mean CPQ11-14.

Table 2. Child Perception Questionnaire 11-14 (short form) scores.

\begin{tabular}{lcc}
\hline Variable & Mean (SD) & Variation \\
\hline Overall mean & $11.9(9.3)$ & $(0 / 42)$ \\
Domain means & & \\
$\quad$ Oral symptoms & $4.6(2.7)$ & $(0 / 12)$ \\
Functional Limitation & $3.1(3.3)$ & $(0 / 16)$ \\
Emotional well-being & $2.9(3.5)$ & $(0 / 13)$ \\
Social well-being & $1.5(1.9)$ & $(0 / 8)$ \\
\hline
\end{tabular}


Table 3. Poisson regression analyses of the association between clinical signs of gingivitis in the anterior region and overall $C P Q$ 11-14 scores.

\begin{tabular}{|c|c|c|c|c|}
\hline Variables & Unadjusted PR (95\%Cl) & $\mathrm{p}$-value & Adjusted PR $(95 \% \mathrm{Cl})$ & $\mathrm{p}$-value \\
\hline \multicolumn{5}{|l|}{ Edema } \\
\hline 1 tertile $(2.77 \%-27.78 \%)$ & 1 & & 1 & \\
\hline 2 tertile $(29.17 \%-54.17 \%)$ & $1.22(1.01-1.45)$ & 0.03 & $1.19(0.94-1.51)$ & 0.13 \\
\hline 3 tertile $(58.33 \%-100 \%)$ & $1.63(1.37-1.93)$ & 0.00 & $1.76(1.39-2.24)$ & 0.00 \\
\hline \multicolumn{5}{|l|}{ Alteration of color } \\
\hline 1 tertile (0-12.5\%) & 1 & & 1 & \\
\hline 2 tertile (13.4\% - 29.2\%) & $1.68(1.43-1.98)$ & 0.00 & $1.23(0.99-1.51)$ & 0.06 \\
\hline 3 tertile $(30.5 \%-91.7 \%)$ & $0.99(0.82-1.19)$ & 0.91 & $0.66(0,51-0.86)$ & 0.01 \\
\hline \multicolumn{5}{|l|}{ Gingival bleeding } \\
\hline 1 tertile $(15 \%-40.28 \%)$ & 1 & & 1 & \\
\hline 2 tertile $(44.44 \%-63.89 \%)$ & $1.26(1.06-1.50)$ & 0.01 & $1.32(1.08-1.61)$ & 0.01 \\
\hline 3 tertile $(65.28 \%-100 \%)$ & $1.13(0.95-1.35)$ & 0.15 & $1.27(1.00-1.62)$ & 0.05 \\
\hline
\end{tabular}

Variables were adjusted for family income, untreated caries, sex, and plaque; PR: prevalence ratio; $p$-value $\leq 0.05$ was considered statistically significant in multivariate analysis.

\section{Discussion}

This is the first study to investigate the relationship between gingival edema in the anterior region and OHRQoL of adolescents. The results obtained suggest that edema and gingival bleeding in the anterior region have a negative impact on the oral health related quality of life of adolescents.

This study indicated that individuals with a higher number of sites with gingival edema in the anterior region have a worse OHRQoL. This can be explained by the fact that the general appearance and the smile are prioritized in adolescence. The appearance impacts their daily social life because it influences their social relations, well-being, and happiness. ${ }^{29,30}$ Esthetic conditions related to gingival health are an essential component of the smile. In this sense, an irregular gingival line becomes a problem to individuals as it prevents an attractive smile. ${ }^{31}$

A previous study also demonstrated that a higher impact on the OHIP-14 was observed in individuals who presented higher levels of anterior gingival enlargement and were under orthodontic treatment. ${ }^{32}$ Another study concluded that excessive gingival display affected the smile esthetics and the OHRQoL of young adults..$^{33}$ These findings may be justified by the fact that increased gingival volume and gingival exposure are characteristics that are often easier to see compared to color changes caused by gingival inflammation. ${ }^{33}$

Color alterations was associated with lower OHRQoL scores. This can be explained by the difficulty in distinguishing a healthy gingiva from an unhealthy one through its color. On the other hand, the presence of gingival edema can be noticed by swelling, loss of gingival contour, and presence of rounded papillae. ${ }^{31}$ In addition, in a cross-sectional study in younger adults in Croatia, a relationship between teeth color and OHRQoL was not found. The authors concluded that color evaluation is complex and depends on the stimulus, sensation, and perception of the observer. ${ }^{34}$ This hypothesis may explain the association found in this research between color alteration and OHRQoL.

As in the present study, the majority of studies use a 15\% bleeding rate as a criterion to define gingivitis. $6,7,8$ The prevalence of gingivitis found in this study was similar to some previous studies. ${ }^{78}$ However, the different criteria for defining gingivitis may explain the different results from other studies., ${ }^{90,11,12}$

Previous reports have also shown that gingival bleeding affects the OHRQoL of adolescents. ${ }^{78}$ This can occur because they are concerned with their gums bleeding during tooth brushing or because the bleeding can influence psychological aspects of 
adolescent life. ${ }^{7}$ In addition, this association can be justified by the emotional and social aspects in the daily life of adolescents. ${ }^{8}$.In a cross-sectional study, other authors also found that dental disorders affect the esthetics and psychosocial behaviors of adolescents compromising their self-esteem and their OHRQoL. ${ }^{35}$

However, the results of this study should be analyzed with some caution. The main study limitation is the small sample size. Our results indicate that bleeding and gingival edema in the anterior region are associated with a worse OHRQoL in adolescents, however further studies with larger samples are needed to confirm these findings.

Our convenience sample included patients with social and economic vulnerability and a high disease burden. This may have influenced the self-perception of oral health because poor socioeconomic status and poor dental status have a negative impact on OHRQoL of adolescents. ${ }^{8}$ In addition, the criterion universally used for gingival health in epidemiological studies is probing because it is quick and easy to perform ${ }^{26}$. Also, clinical examinations of color alteration and edema used in this study may be difficult to reproduce outside the clinical setting. In epidemiological studies, the examiners normally do not have enough time to perform a clinical evaluation and they use natural lighting. However, in the clinical setting, dentists can use these exams to monitor gingivitis and explain to adolescents that these are signs of disease that can affect the esthetics of their smile and their OHRQoL. Furthermore, the prevalence of early periodontitis is associated with the prevalence of gingivitis during childhood and adolescence. ${ }^{36}$ Therefore, it is important to emphasize that dental visits during adolescence is essential to reduce oral health problems and promote good hygiene habits in adulthood.$^{37}$ Therefore, it is important that adolescents have periodontal evaluation routinely. ${ }^{38}$

In conclusion, our results provide evidence that edema and marginal bleeding of the gingival tissues influence self-perception of oral health of adolescents. This must be considered when professionals are planning and performing dental interventions aiming at improving oral health status and increasing the adherence to dental treatment.

\section{Conclusion}

The results of the present study indicate that gingival edema and marginal bleeding of gingival tissues in the anterior region may have a negative impact in the way adolescents perceive their oral health, affecting their quality of life.

\section{References}

1. Glick M, Williams DM, Kleinman DV, Vujicic M, Watt RG,

Weyant RJ. A new defnition for oral health developed by the FDI World Dental Federation opens the door to a universal defnition of oral health. J Public Health Dent. 2017 Dec;77(1):3-5. https://doi.org/10.1111/iphd.12213

2. Group TH. The World Health Organization quality of life assessment (WHOQOL): position paper from the World Health Organization. Soc Sci Med. 1995 Nov; 41(10):1403-9.

3. Mcgrath C, Bedi R. A national study of the importance of oral health to life quality to inform scales of oral health related quality of life. Qual Life Res. 2004 May;13(4):813-8. https://doi.org/10.1023/B:QURE.0000021696.05528.4c

4. Sischo L, Broder HL. Oral health-related quality of life: what, why, how, and future implications.

J Dent Res. 2011 Nov;90(11):1264-70.

https://doi.org/10.1177/0022034511399918.
5. Ministério da Saúde (BR). Secretaria de Vigilância em Saúde. Departamento de Atenção Básica. Projeto SBBrasil 2010: resultados principais. Brasília, DF: Ministério da Saúde; 2011.

6. American Dental Association. Acceptance program guidelines: toothbrushes. Chicago: American Dental Association. 1998

7. Krisdapong S, Prasertsom P, Rattanarangsima K, Sheiham A, Tsakos $G$. The impacts of gingivitis and calculus on Thai children's quality of life. J Clin Periodontol. 2012 Sep;39(9):83443. https://doi.org/10.1111/j.1600-051X.2012.01907.x

8. Tomazoni F, Zanatta FB, Tuchtenhagen S, Rosa GN, Del Fabro JP, Ardenghi TM..Association of gingivitis with child oral healthrelated quality of life. J Periodontol. 2014 Nov;85(11):1557-65. https://doi.org/10.1902/jop.2014.140026

9. Chiapinotto FA, Vargas-Ferreira F, Demarco FF, Corrêa FO, Masotti AS. Risk factors for gingivitis in a group of Brazilian schoolchildren. J Public Health Dent. 2013;73(1):9-17. https://doi.org/10.1111/iphd.12001 
10. Rodan R, Khlaifat F, Smadi L, Azab R, Abdalmohdi A. Prevalence and severity of gingivitis in school students aged 6-11 years in Tafelah Governorate, South Jordan: results of the survey executed by National Woman's Health Care Center. BMC Res Notes. 2015 Nov;8:662. https://doi.org/10.1186/s13104-015-1532-y

11. Sharva V, Reddy V, Bhambal A, Agrawal R. Prevalence of gingivitis among children of urban and rural areas of Bophal District, India. J Clin Diagn Res. 2014 Nov; 8(11):ZC52-4. https://doi.org/10.7860/JCDR/2014/10092.5135

12. Peres MA, Peres KG, Cascaes AM, Correa MB, Demarco FF, Hallal PC, Horta BL, Gigante DP, Menezes AB. Validity of partial protocols to assess the prevalence of periodontal outcomes and associated sociodemographic and behavior factors in adolescents and young adults. J Periodontol. 2012 Mar;83(3):369-78. https://doi.org/10.1902/jop.2011.110250

13. Gesse HC, Peres MA, Marcenes W. Gingival and periodontal conditions associated with socioeconomic factors. Rev Saúde Pública. 2001 Jun;35(3):289-93. https://doi.org/10.1590/S0034-89102001000300012

14. Vettore MV, Marques RA, Peres MA. [Social inequalities and periodontal disease: multilevel approach in SBBrasil 2010 survey]. Rev Saude Publica. 2013 Dec;47 Suppl 3:29-39. Portuguese.

15. Tomazoni F, Vettore MV, Zanatta FB, Tuchtenhagen S, Moreira $\mathrm{CH}$, Ardenghi TM. The associations of socioeconomic status and social capital with gingival bleeding among schoolchildren. J Public Health Dent. 2017 Dec;77(1):21-29. https://doi.org/10.1111/iphd.12166

16. Vazquez FL, Cortellazzi KL, Kaieda AK, Guerra LM, Ambrosano GM, Tagliaferro EP et al. Quality of life and socio-dental impact among underprivileged Brazilian adolescents.Qual Life Res. 2015 Mar;24(3):661-9. https://doi.org/10.1007/s11136-014-0795-4

17. Barbosa TS, Gavião MBD, Mialhe FL. Gingivitis and oral health-related quality of life: a systematic literature review. Braz Dent Sci. 2015 Jan/Mar;18(1):7-16. https://doi.org/10.14295/bds.2015.v18i1.1013

18. López R, Baelum VJ. Oral health impact of periodontal diseases in adolescents. J Dent Res. 2007 Nov;86(11):1105-9. https://doi.org/10.1177/154405910708601116

19. Sun L, Wong HM, McGrath CPJ. The factors that influence the oral health-related quality of life in 12-year-old children: baseline study of a longitudinal research. Health Qual Life Outcomes. 2017 Aug 7;15(1):155. https://doi.org/10.1186/s12955-017-0729-2

20. Agência de Desenvolvimento de Santa Maria. Santa Maria em Dados. 2010 [cited 2017 Feb 09] Disponível em: http:// santamariaemdados.com.br/sociedade/8-1-demografia

21. Armitage GC. Development of a classification system for periodontal diseases and conditions. Northwest Dent. 2000 Nov-Dec;79(6):31-5.

22. Instituto Brasileiro de Geografia e Estatística - IBGE. Características étnico-raciais da população: classificações e identidades. 2013 [cited 2017 Feb 09]. Disponível em: https://biblioteca.ibge.gov.br/visualizacao/livros/liv63405.pdf
23. Torres CS, Paiva SM, Vale MP, Pordeus IA, Ramos-Jorge $\mathrm{ML}$, Oliveir AC et al. Psychometric properties of the Brazilian version of the Child Perceptions Questionnaire $\left(C P Q_{11}\right.$. 14): short forms. Health Qual Life Outcomes. 2009;7:43. https://doi.org/10.1186/1477-7525-7-43

24. Goursand D, Paiva SM, Zarzar PM, Ramos-Jorge ML, Cornacchia GM, Pordeus IA et al.Cross-cultural adaptation of the Child Perceptions Questionnaire 11-14 (CPQ $11-14)$ for the Brazilian Portuguese language. Health Qual Life Outcomes. 2008 Jan 14;6:2. https://doi.org/10.1186/1477-7525-6-2

25. Foster Page LA, Thomson WM, Jokovic A, Locker D.Validation of the Child Perceptions Questionnaire $\left(C P Q_{11-14}\right)$. J Dent Res. 2005 Jul;84(7):649-52. https://doi.org/10.1177/154405910508400713

26. World Health Organization. The World Oral Health Report 2003: continuous improvement of oral health in the 21 st century: the approach of the WHO Global Oral Health Programme. Geneva: World Health Organization; 2003.

27. Löe $H$. The gingival index, the plaque index and the retention index system. J Periodontol. 1967 Nov-Dec;38(6): 610-6.

28. Ainamo J, Bay I. Problems and proposals for recording gingivitis and plaque. International Dental Journal 1975; 25(4): 229-35. https://doi.org/10.1902/jop.1967.38.6.610

29. Rossini G, Parrini S, Castroflorio T, Fortini A, Deregibus A, Debernardi CL. Children's perceptions of smile esthetics and their influence on social judgment: $A$ systematic review. Angle Orthod. $2016 \mathrm{Nov}$;86(6):1050-5. https://doi.org/10.2319/102715-722

30. Rosa GN, Del Fabro JP, Tomazoni F, Tuchtenhagen S, Alves LS, Ardenghi TM. Association of malocclusion, happiness, and oral health-related quality of Life (OHRQoL) in schoolchildren, J Public Health. 2016;76(2):85-90. https://doi.org/10.1111/iphd.12111

31. Morley J, Eubank J. Macroesthetic elements of smile design. J Am Dent Assoc. 2001 Jan;132(1):39-45.

32. Zanatta FB1, Ardenghi TM, Antoniazzi RP, Pinto TM, Rösing CK. Association between gingival bleeding and gingival enlargement and oral health-relatedquality of life (OHRQoL) of subjects under fixed orthodontic treatment: a cross-sectional study BMC Oral Health. 2012 Nov; 12:53. https://doi.org/10.1186/1472-6831-12-53

33. Antoniazzi RP, Fischer LS, Balbinot CEA, Antoniazzi SP, Skupien JA. Impact of excessive gingival display on oral health-related quality of life in a southern brazilian young population. J Clin Periodontol. 2017Oct;44(10):996-1002. https://doi.org/10.1111/jcpe.12753

34. Kovacevic Pavicic D, Pavlic A, Kinkela Devcic M, Lajnert V, Spali S. Tooth color as a predictor of oral health-related quality of life in young adults. J Prosthodont. 2017 Oct 31. https://doi.org/10.1111/jopr.12666

35. Kaur P, Singh S, Mathur A, Makkar DK, Aggarwal VP, Batra M et al. Impact of dental disorders and its influence on self esteem levels among adolescents. J Clin Diagn Res. 2017 Apr;11(4):ZC05- 8. https://doi.org/10.7860/JCDR/2017/23362.9515 
- Edema and gingival bleeding in anterior region have a negative influence on quality of life of adolescents

36. Yang NY, Zhang Q, Li JL, Yang SH, Shi Q. Progression of periodontal inflammation in adolescents is associated with increased number of Porphyromonas gingivalis, Prevotella intermedia,Tannerella forsythensis, and Fusobacterium nucleatum. Int J Paediatr Dent. 2014 May;24(3):226-33. https://doi.org/10.1111/ipd.12065.

37. Crocombe LA, Broadbent JM, Thomson WM, Brennan DS, Poulton R. Impact of dental visiting trajectory patterns on clinical oral health and oral health- related quality of life. J

Public Health Dent. 2012;72(1):36-44. https://doi.org/10.1111/j.1752-7325.2011.00281.x

38. Drummond BK, Brosnan MG, Leichter JW. Management of periodontal health in children: pediatric dentistry and periodontology interface. Periodontol 2000. 2017 Jun;74(1):158-67. https://doi.org/ 10.1111/prd.12195 